\title{
Generic guidance on the lifting of emergency countermeasures
}

\author{
A.F. NISBET ${ }^{1}$, H. ROCHFORD ${ }^{1}$, T. CABIANCA ${ }^{1}$, A. OUDIZ ${ }^{2}$, G. KIRCHNER $^{3}$,

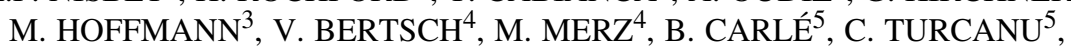

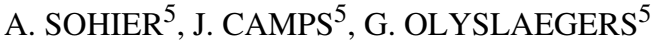

\begin{abstract}
Generic guidance on the withdrawal of sheltering, withdrawal of evacuation and evacuation of sheltered populations (displacement) has been developed based on previously unpublished work in the UK and France and on input from stakeholder panels in Germany, Belgium, France and the UK. The guidance is a living document that can be developed further in the future, both in its generic form and also as customised versions in some Member States. The guidance outlines the many factors which influence the withdrawal of emergency countermeasures: official confirmation that any release has stopped; adequacy of monitoring data; radiological criteria; radiological protection advice; availability of resources; social and psychological needs; stakeholder dialogue; and communication strategy. The relative importance placed by decision makers on each of these criteria would vary according to the nature and scale of the accident and also on socio-political, economic and cultural perspectives. In the event of a radiological incident, decision makers will need to be in a position to construct a strategy for managing the withdrawal of emergency countermeasures. For larger scale, longer duration releases involving several nuclides, a management strategy is likely to be complex. The guidance therefore includes a series of checklists which have been developed in conjunction with stakeholders to take into account the main criteria and factors which should be considered.
\end{abstract}

\section{Introduction}

In the event of an incident involving the release of radionuclides into the environment, interventions such as sheltering and evacuation may be implemented urgently to avoid serious deterministic injuries and to keep the risk of stochastic health consequences as low as reasonably achievable. Such measures will follow procedures planned in advance. As the emergency progresses and understanding of the circumstances increases, decisions will increasingly be based on actual data rather than on assumptions and model predictions. The decision to withdraw emergency countermeasures will need to appropriately reflect the prevailing circumstances. Many different aspects must be taken into account when reaching

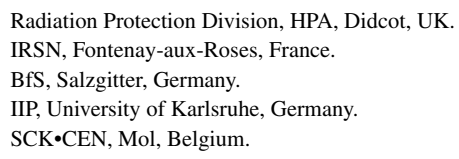


such decisions: radiological protection should be considered as only one part of the protection strategy.

The EURANOS project provided an opportunity for developing generic guidance on the issues surrounding the withdrawal of emergency countermeasures (Nisbet et al., 2008). The guidance draws on unpublished work carried out in the UK and France, and also on the recently published recommendations of the International Commission on Radiological Protection, Publication 103 (ICRP, 2007), as well as input from stakeholder panels in UK, France, Germany and Belgium. The main features of the guidance are summarised here. The administration of stable iodine tablets to block uptake of radioactive iodine by the thyroid is not considered as part of this guidance as iodine prophylaxis tends to be a one-off countermeasure which does not need to be lifted.

\section{Factors influencing the withdrawal of emergency countermeasures}

Eight criteria that should be considered before withdrawing emergency countermeasures have been identified and are described below. The relative importance placed by decision makers on each of these criteria would vary according to the nature and scale of the accident and also on socio-political, economic and cultural perspectives.

\subsection{Official confirmation that the release has stopped}

Official confirmation (e.g. a formal statement from the authorities responsible for the safety of the installation), that the release has stopped and is unlikely to recur, and that the plant has been brought under control, is a necessary condition for the withdrawal of emergency countermeasures.

\subsection{Adequacy of monitoring data}

Monitoring data are required to support decisions on withdrawing emergency countermeasures. The type of information that will be available to aid decisions on withdrawing advice on sheltering and evacuation is likely to be quite different for the two countermeasures because of the timescales involved. For sheltering, the monitoring will be indicative rather than comprehensive, being based on initial measurements of atmospheric concentrations and wind direction, ambient dose rates and surface contamination in different sectors of the area affected. To determine if evacuated people can return home, much more detailed monitoring is required. Measurements should be at locations where people spend their time 
outside their homes (e.g. roads, gardens, shops, schools, nurseries, playgrounds), and also in indoor locations. The monitoring strategy may initially concentrate on characterising areas where contamination is expected to be low, with a view to an early return of evacuees, rather than obtaining detailed information on contamination levels in areas where it is not expected that evacuees would be allowed to return prior to the implementation of decontamination measures. Relevant measurements are: ground deposition levels; ambient dose rates; airborne radionuclide concentrations; food, water and surface contamination levels.

\subsection{Radiological criteria}

A major feature of the new ICRP (2007) recommendations is the emphasis on overall optimisation of the response strategy in emergency response situations using reference levels. A reference level represents the level of dose or risk above which it is judged to be inappropriate to plan to allow exposures to occur. ICRP recommends that during planning for emergency response, a reference level of typically between 20 to $100 \mathrm{mSv}$ effective dose (acute or per year, as applicable to the emergency exposure situation under consideration) should be selected for public exposures. The reference level selected will act as a benchmark against which to judge the optimisation of the protection strategy applied. When it has been agreed that the incident has moved from an emergency exposure situation to an existing exposure situation, ICRP advises that a reference level for the overall effective dose would most likely be set in the band 1 to $20 \mathrm{mSv} / \mathrm{year}$. No specific reference levels have been set by ICRP to aid decisions on withdrawal of sheltering or evacuation. An example of how reference levels may be used as part of the decision making process is presented in Table I.

\subsection{Radiation protection advice}

Sheltering is not a long-term protective measure and cannot easily be maintained for periods of more than a day or so. Furthermore, the protection afforded by sheltering tends to decrease with time, due to the movement of radionuclides into buildings. If the release has been short, depending on the monitoring information on contamination levels in the area after the release has stopped, it may be possible to withdraw sheltering relatively quickly and advise people that it is safe to go outdoors and return to normal living. This may be subject to some restrictions that could be imposed (e.g. taking off shoes before entering houses). Lifting of sheltering should be accompanied by advice to ventilate buildings. If the release is expected to be prolonged, sheltering may be replaced by displacement ${ }^{6}$ while the

6 Displacement refers to the evacuation of persons previously sheltering in an area. 
TABLE I

Illustrative reference levels for withdrawal of sheltering - based on short-term ${ }^{1}$ measurements.

\begin{tabular}{ll}
\hline $\begin{array}{l}\text { Predicted effective dose } \\
\text { (projected or residual) }\end{array}$ & Action \\
\hline$<20 \mathrm{mSv} / \mathrm{y}$ or acute & $\begin{array}{l}\text { The local population should be advised that they may remain in the } \\
\text { affected area after withdrawal of sheltering. }\end{array}$ \\
\hline $20-100 \mathrm{mSv} / \mathrm{y}$ or acute & $\begin{array}{l}\text { The local population should be either advised that they may remain } \\
\text { in the area out of shelter, or that they may be displaced (evacuated). } \\
\text { In making this decision, it is important to take account of the number } \\
\text { of people directly affected and the capability of local authorities to } \\
\text { provide acceptable temporary accommodation as quickly as possible. }\end{array}$ \\
$\begin{array}{l}\text { Otherwise if the population remain, recovery measures should be } \\
\text { implemented as soon as possible to optimise protection. }\end{array}$ \\
\hline $100 \mathrm{mSv} / \mathrm{y}$ or acute & The population should be rapidly displaced. \\
\hline
\end{tabular}

${ }^{1}$ Sheltering will have been withdrawn by the time long term measurements are available.

2 The projected dose is the dose that would be expected to be incurred if no protective measures(s) were to be taken. This can give an initial indication of the scale of the response required and may be compared with the reference level in the early stages of an emergency exposure situation. The residual dose is the dose expected to be incurred after protective measure(s) have been fully implemented (or a decision has been taken not to implement any protective measures).

release is still taking place or this may happen if the release has stopped but the residual contamination levels are high.

Before sheltering can be withdrawn, information on the short-term radiological exposure resulting from the population remaining in the area $(e . g$. in 1 st week and 1 st month) is required, in addition to projections of dose over longer periods such as a year. Radiological protection experts would draw on their knowledge of accidental releases and would use measurements taken in the early phase once the release had stopped. The area may be divided into a number of sectors for which specific dose calculations would be performed. The predictions are likely to be quite uncertain and this should be taken into account through scoping calculations. Radiological protection advice for the withdrawal of sheltering would then follow one of the two following options:

- Where the authorities consider that short-term exposure will not pose a significant risk for health, they may decide to advise that the population can remain in the area. In the longer-term, it would be necessary to predict individual effective doses taking into account any recovery options that could be implemented.

- Where the authorities consider the short-term exposure might be significant, they may decide to displace (evacuate) the population when the sheltering advice is withdrawn. The decision would need to take into account the number of people concerned and the capacity of the authorities to rapidly identify and equip reception centres for stays of several days to several weeks for this number of people. In planning, particular attention should be given to evacuation of hospitals, homes for the aged and schools, including providing 
information for their parents. Radiological protection advice may recommend that decontamination options are carried out in the contaminated area whilst people are away from their homes.

Evacuation is particularly effective in terms of avoiding radiation exposure if it can be taken as a precautionary measure before the release starts. It is difficult to maintain for periods of more than about one week, although it may be necessary to keep residents away from their homes for longer than this due to the levels of deposited activity or continued threat from the plant. It may be appropriate to predict individual effective doses for different age groups after their possible return to the area, taking into account any recovery options already implemented and those that have agreed to be implemented during consultation.

\subsubsection{Partial withdrawal of emergency countermeasures}

There are situations where it may be appropriate to withdraw emergency countermeasures for some groups of people, whilst continuing to recommend they be left in place for other groups. However, this must be accompanied by prospective dose assessments with advice on the likely risks to those involved. Partial withdrawal of sheltering advice could be allowed on a one-off basis to support the reunion of separated family members, in particular children with parents. Similarly for those requiring medical supplies, it may be possible for emergency personnel to be available to provide essential supplies to those who are sheltering. Other types of conditional withdrawal of sheltering are possible, for example, limiting time spent outdoors or advice to remove shoes before going indoors. However, such situations may be difficult to manage. Providing supervised re-entry into an evacuated area for limited periods, whether to collect belongings, to check the security of property or to attend to the needs of animals may substantially reduce the pressure for early withdrawal of evacuation advice.

\subsection{Availability of resources}

It is important to note that resources are needed to plan and undertake monitoring; to interpret monitoring data; and to carry out dose assessments before any advice on withdrawing emergency countermeasures can be given. The resources required for the subsequent withdrawal of sheltering principally focus on a mechanism to communicate with the sheltered population. The return of evacuated populations to their homes requires mechanisms to communicate with the evacuees and additional resources in terms of manpower and transport to bring them home. 


\subsection{Social and psychological needs}

Particular issues for sheltering are the need to reunite children with parents, the needs of farmers to tend to their livestock and the need to provide the necessary medical supplies to those who are sheltered. The evacuation or displacement of residents from their homes for periods of days or even weeks can also cause high levels of stress. Concern for the security of homes, restricted access to personal possessions and anxiety over animal welfare (including pets as well as farm animals) are particular issues for evacuation.

\subsection{Stakeholder dialogue}

As emergency countermeasures have to be initiated promptly and prescriptively, it is important to involve stakeholders at the planning stage to help determine appropriate reference levels for emergency exposure situations and trigger levels for the implementation of emergency countermeasures. Withdrawal of advice to shelter will probably be carried out without significant interaction with members of the public, because of the short timescales required, although other stakeholders such as responders will be closely involved. It is therefore important that criteria for withdrawal are discussed with the public at the planning stage. In contrast, return of evacuated populations will almost certainly involve more extensive consultation with those affected before any decisions on the timescale for their return are made.

\subsection{Communication strategy}

The provision of information and how the information is communicated will have a significant influence on how the authorities tackle the situation, on the response of society to the event and on the overall success of the management strategy. Knowledge will be limited in the early phase of an accident and information should properly reflect such uncertainties and any advice given should err on the side of caution. For those sheltering, radio and television broadcasts as well as the internet can provide information on the actions being taken, the timescales for decisions and any further options that are being considered. For those evacuated, reception centres will provide information on the timescales for returning home based on detailed monitoring data, radiological assessments and the requirements to carry out further decontamination measures

\section{Datasheets}

A datasheet template, similar in format to those used in the generic European handbooks for food production systems, inhabited areas and drinking water 
TABLE II

Checklist for withdrawal of sheltering (no displacement).

\begin{tabular}{|c|c|}
\hline Criteria & Factors to consider \\
\hline \multirow{3}{*}{$\begin{array}{l}\text { Confirmation that the plant has } \\
\text { been made safe }\end{array}$} & Has the plume moved out of the area and is it unlikely to return? \\
\hline & Is the incident at the plant under control? \\
\hline & Are no further releases likely? \\
\hline \multirow[t]{3}{*}{ Adequacy of monitoring data } & Are reliable and indicative measurements available? \\
\hline & Are measurements available within and adjacent to the area? \\
\hline & Can the monitoring data be visualised on a suitable medium (e.g. maps)? \\
\hline \multirow[t]{3}{*}{ Radiological criteria } & Estimation of residual doses for comparison with reference levels if specified. \\
\hline & $\begin{array}{l}\text { Comparison of contamination levels or ambient dose rates with an agreed set of } \\
\text { trigger levels for the lifting of sheltering, if specified. }\end{array}$ \\
\hline & $\begin{array}{l}\text { Comparison of contamination levels or ambient dose rates with an agreed set of } \\
\text { triggers levels for displacement of sheltered populations. }\end{array}$ \\
\hline Radiological protection aspects & $\begin{array}{l}\text { Options for further reducing exposures (e.g. decontamination of public places, } \\
\text { roads, gardens, schools, playgrounds, restrictions on behaviours). }\end{array}$ \\
\hline \multirow[t]{2}{*}{ Availability of resources } & Resources to continue monitoring after withdrawal of sheltering. \\
\hline & Mechanism for communicating with sheltered populations. \\
\hline \multirow[t]{5}{*}{ Social and psychological needs } & Requirements for reuniting of families. \\
\hline & Requirements for urgent medical supplies for existing medical conditions. \\
\hline & Requirements for urgent medical attention, not related to incident. \\
\hline & Requirements for farmers to tend to livestock. \\
\hline & Concern of affected people about impact of accident on their health. \\
\hline Stakeholder dialogue & $\begin{array}{l}\text { Identify affected population and initiate dialogue with authorities as soon as } \\
\text { possible. }\end{array}$ \\
\hline Communication strategy & Use any pre-established mechanisms. \\
\hline
\end{tabular}

(Nisbet et al., 2010) was used to systematically record information on the withdrawal of emergency countermeasures. Two datasheets are presented in the guidance document (Nisbet et al., 2008), one for the withdrawal of advice to shelter, the other for withdrawal of advice to evacuate or displace. The datasheets include a short description of the option, its key attributes, constraints, radiological criteria, feasibility, requirements, costs, side effects, and a summary of practical experience of implementing the option.

\section{Decision-aiding checklists}

A series of checklists have been developed in conjunction with stakeholders taking into account the main criteria that should be considered before a decision is taken to withdraw sheltering or evacuation advice. The checklist for sheltering (assuming no subsequent displacement) is given in Table II. 


\section{Conclusions}

Generic guidance on the withdrawal of sheltering and evacuation has been developed (Nisbet et al., 2008) based on previously unpublished work in the UK and France and on input from stakeholder panels in Germany, Belgium, France and the UK. The guidance outlines the many factors which influence the withdrawal of emergency countermeasures and provides datasheets for each option and checklists of the main criteria to be considered. The guidance is a living document that can be developed further in the future, both in its generic form and also as customised versions in some Member States.

Acknowledgements. The development of guidance on the withdrawal of emergency countermeasures received partial financial support from the European Commission Sixth Framework Programme (Nuclear Fission/Radiation Protection) under the EURANOS integrated project: European approach to nuclear and radiological emergency management and rehabilitation strategies (Contract No: FI6R-CT-2004-508843).

\section{REFERENCES}

ICRP Publication 103 (2007) Recommandation of the International Commission on Radiological Protection, Ann. ICRP 37 (2-3).

Nisbet A.F., Brown J., Howard B.J., Beresford N.A., Ollagnon H., Turcanu C., Camps J., Andersson K., Rantavaara A., Ikäheimonen T., Duranova T., Oughton D., Kirchner G., Papachristodoulou C., Ioannides K., Kwakman P. (2010) Decision aiding handbooks for managing contaminated food production systems, drinking water and inhabited areas in Europe, Radioprotection 45, S23-S37.

Nisbet A.F., Rochford H., Cabianca T., Oudiz A., Kirchner G., Hoffmann M., Bertsch V., Merz M., Carlé B., Turcanu C., Sohier A., Camps J., Olyslaegers G. (2008) Generic Guidance for Assisting in the Withdrawal of Emergency Countermeasures in Europe Following a Radiological Incident. EURANOS(CAT1)-TN(08)06. Available from http://www.euranos. fzk.de/ 